\title{
Impact of Processing on Flavor Volatiles and Physicochemical Properties of Pomegranate Juice
}

\author{
Hayam Allam \\ Institute of Food Technology Research, Agriculture Research Center, Ministry of Agriculture Giza, Egypt
}

Received: $10 / 12 / 2016$

\begin{abstract}
This study was undertaken to investigate the effect of pasteurization and concentration techniques on some physicochemical parameters, volatile flavor compounds and polyphenols composition of clear pomegranate juice and to evaluate the use of cut-back process for improving the quality of the juice concentrate. The results showed no marked changes could be observed in titratable acidity, total sugars and $\mathrm{pH}$ value, whereas ascorbic acid content and color parameters of the juice were affected by pasteurization. A total of 27 compounds were identified in fresh pomegranate juice: 7 monoterpenes, 6 esters, 5 aldehydes, 3 alcohols, 4 ketone, 1 ether and 1 alkane hydrocarbon. Concentration and pasteurization processes resulted in loss of the two major aroma compounds (Ethyl acetate and Ethyl propanoate) whereas pasteurization alone resulted in loss of one monoterpene (3-Carene). Pomegranate juice prepared by cut-back process retained all the 27 aroma compounds found in fresh juice but in slightly lower concentration. Twenty three phenolic compounds were identified and quantified in pomegranate juice. Pyrogallol was the predominating polyphenol in addition to varying concentrations of gallic acid, 4 Epi-catechin, 4-amino benzoic, protocatchouic, catechin, chlorogenic acid, chatechol, P-OH-benzoic acid, ellagic acid, P-coumaric acid and ferulic acid. Concentration process resulted in considerable increase in polyphenols concentration whereas pasteurization lowered its concentration to a great extent. The highest polyphenol concentration was found in pomegranate juice from cut-back process. It is to be concluded that cut-back process could be a promising process in producing better quality juice.
\end{abstract}

Keywords: Pomegranate juice, concentrate, volatile compounds, polyphenols, cut-back process

\section{INTRODUCTION}

Pomegranate (Punica granatum L.) is a member of the Punicaceae family and is considered one of the oldest cultivated edible fruit. The annual world production of pomegranate fruit is estimated to be 3 million metric tons (Kahramanoglu and Usanmaz, 2016). Global demand to pomegranate is increasing due to its functional properties with nutritional and health benefits in the human diet (Caleb et al., 2015). Pomegranate fruit and its juices are being widely promoted to consumers as one of the new "super food" capable of addressing a huge variety of health disorders (Johanningsmeier and Harris, 2011).

Pomegranate juice is the most popular and extensively studied pomegranate-based product (Carbonell-Barrachina et al., 2012; Nuncio-Jauregui et al., 2014).Pomegranate juice is defined as unfermented juice obtained from mature and sound fruit by mechanical processes and is preserved by physical means, such as pasteurization (AIJN, 2008). Processing of pomegranate juice has some negative effects on juice quality parameters (color and aroma). This effect was different depending on the processing operations used. Pasteurization and concentration of pomegranate juice had an impact on flavor volatiles, polyphenols composition, antioxidants activity, anthocyanin and vitamins (Alper et al., 2005; Fischer et al., 2011; Ashoush and Gadallah, 2012; Yousefi et al., 2012; Koppel et al., 2015). Fruit juices have been traditionally concentrated by multi-stage vacuum evaporation, resulting in a loss of fresh juice flavors, color degradation and a "cooked" taste due to the thermal effects (Jiao et al., 2004).

The aroma of pomegranate juice had been attributed to the presence of various volatile compounds, including esters, alcohols, aldehydes, ketones, and terpenes, which provide a mixture of various "green", "woody", "earthy", "fruity", "floral", "sweet" and "musty" notes (Mayuoni-Kirshinbaum and Porat, 2014). Calín-Sánchez et al. (2011) reported that the overall liking of the juice was found to be related to the attribute of "fresh flavor" and "fresh odor" which in turn seemed to be due to the presence of some volatile compounds, mainly terpenes ( $\alpha$-pinene, $\beta$-pinene, $\beta$ myrcene, limonene and $\gamma$-terpinene). They identified a total of 18 compounds were found in pomegranate aroma profiles, including monoterpenes, aldehydes, alcohols, monoterpenoids and linear hydrocarbons. The most abundant compound was trans-2-hexenal, 3carene, $\alpha$-terpinene and $\alpha$-terpineol. Impact of preharvest and postharvest factors on changes in volatile compounds of pomegranate products (Caleb et al., 2015), the effect of method of extraction on volatile compounds (Zhiying et al., 2016), and the effect of different maturity stages and growing locations on change in volatile compounds (Mphahlele et al., 2016) have been extensively studied. The influence of pasteurization and concentration on volatile flavor compounds of clear pomegranate juice has not been thoroughly investigated.

One of the main constituents responsible for the functional properties of pomegranate juice, are phenolic compounds which act as chain breaking antioxidant because of their hydroxyl group scavenges reactive radicals (Halliwel, 2002). Pomegranate juice obtained by squeezing the whole fruit has the highest concentration of ellagitannins than any commonly consumed juice and contains the unique ellagitannin, punicalagin (Heber, 2011). According to Alper et al. (2005) the thermal treatment applied to pomegranate juice produced by different clarification methods affected their total phenol content. 
Different technological approaches have been developed and implemented to overcome the negative effects of pasteurization and concentration of fruit juices (Shatta, 2006). Unpasteurized juices packaged in polyethylene bottles are now occupying a great segment of the fruit and vegetable juice market (Fellers, 2006). The shelf life of these juices depends primarily on storage temperature. Freeze concentration systems (FCS) are implemented in the fruit juice industry (Sanchez et al., 2009). Freeze-concentrated fruit juices are characterized by high nutritional value and sensory quality due to low processing temperatures which alter undesirable chemical changes. Membrane processes such as membrane distillation (MD), reverse osmosis (RO), and pervaporation have been recognized as alternative membrane based separation and concentration processes in fruit juice (Cassano et al., 2011; Kumar et al., 2013). Sixty five years ago, cutback process was developed to overcome the flavor deterioration of orange juice concentrate as a result of concentration by evaporation (Ashurst, 2013). The process is still in use today for the production of frozen concentrated orange juice (FCOJ). It involves adding fresh unpasteurized orange juice (called cut-back juice) to orange juice concentrate of $58^{\circ}$ Brix before freezing to reduce its concentration to $42^{\circ}$ Brix giving four-fold concentrated FCOJ. The later concentrate is packed in $350 \mathrm{~mL}$ enameled cans and for reconstitution amount of water equals 3 times the volume of the can is added. The cut-back process was not implemented, so far, for other fruit juices.

This study was undertaken to investigate the effect of pasteurization and concentration processes on volatile flavor compounds, polyphenols composition and some physicochemical properties of clear pomegranate juice and to evaluate the cut-back process for improving the quality of the reconstituted juice.

\section{Materials:}

\section{MATERIALS AND METHODS}

Pomegranate fruits (Manfaluti cultivar) were purchased from whole sale market (El-obour, Egypt) at commercially ripening stage.

\section{Methods:}

\section{Preparation of pomegranate juice and concentrate:}

Fresh pomegranate fruits were washed and cut into two halves. The arils were separated manually and juice was extracted using Braun Juice Extractor (Type: MP 50, Germany). The resultant turbid juice was centrifuged at $5000 \mathrm{rpm}$ for $15 \mathrm{~min}$. The obtained clear juice (Fresh Juice, F) was concentrated in a laboratory rotary vacuum evaporator rotating at $40^{\circ} \mathrm{C}$ to final total soluble solids (TSS) of $60^{\circ}$ Brix. Reconstituted Juice (R) was prepared from juice concentrate by adding the amount of water to bring the TSS of the juice to the level of the fresh juice $\left(16.1^{\circ}\right.$ Brix). Pasteurization of fresh pomegranate juice $(\mathrm{F} 1)$ and reconstituted juice (R1) was performed at $87^{\circ} \mathrm{C}$ for $5 \mathrm{~min}$ (Alper et al., 2005).

\section{Preparation of pomegranate juice using cut-back process:}

One volume of fresh unpasteurized pomegranate juice was added to 3 volume of pomegranate concentrate. The resultant concentrate $\left(48.5^{\circ}\right.$ Brix $)$ was packaged in polyethylene bags (each contained $100 \mathrm{ml}$ ), subjected to freezing at $-18^{\circ} \mathrm{C}$ and stored at the same temperature. For the preparation of the single strength juice two volumes of water $(200 \mathrm{ml})$ were added to one volume of the frozen concentrate to obtain ready to drink juice of $16.1^{\circ}$ Brix.

\section{Physicochemical analysis}

Pomegranate juices were analyzed for $\mathrm{pH}$ (Jenway $\mathrm{pH}$ meter, UK). Total soluble solids content were measured with an Abbe refractometer (Bellingham and Stanley Ltd.) at $20^{\circ} \mathrm{C}$ with values being expressed as ${ }^{\circ}$ Brix. Titratable acidity was determined according to FSSAI (2012) by acid-base potentiometer $(\mathrm{NaOH}, 0.1 \mathrm{~N}$ up to a $\mathrm{pH}$ value of 8.1) and expressed as gram anhydrous citric acid per $100 \mathrm{ml}$ juice, total sugars and ascorbic acid contents were determined according to AOAC (2005). Color was measured in juices using the CIE (Committee International d'Eclairage) $\mathrm{L}^{*}, \mathrm{a}^{*}$, and $b^{*}$ coordinates in a glass- sample cup using Hunter Lab Spectrophotometric colorimeter (Hunter Lab Color Flex EZ, USA). The instrument was calibrated by white, black and red tiles at illuminant $\mathrm{D}^{65}$ and $10^{\circ}$ observer according to McLaren (1980). The $\mathrm{L}^{*}$ value indicates lightness, $a^{*}$ value indicates redness to greenness and $b^{*}$ value indicates yellowness to blueness.

\section{Extraction of volatile compounds}

The aroma volatiles of pomegranate juices were isolated using a dynamic headspace system. The samples were purged for 3 hours with nitrogen gas (purity $>99.99 \%$ ) at a flow rate of $100 \mathrm{ml} / \mathrm{min}$. The headspace volatiles were swept into cold trap containing diethyl ether and pentane $(1: 1, \mathrm{v} / \mathrm{v})$ and hold at $-10^{\circ} \mathrm{C}$. The solvents containing the volatiles were dried over anhydrous sodium sulfate for one hour. The volatiles were obtained by evaporation of the solvents under reduced pressure (Güler, 2007).

\section{Gas Chromatography (GC) analysis}

Gas chromatography analysis was performed using Perkin Elmer Auto system equipped with flame ionization detector (FID). A fused silica capillary column DB-5 (60 m X $0.32 \mathrm{~mm}$ i.d) was used. The oven temperature was maintained initially at $50^{\circ} \mathrm{C}$ for $10 \mathrm{~min}$, then programmed from 50 to $180^{\circ} \mathrm{C}$ at a rate of $3^{\circ} \mathrm{C} / \mathrm{min}$. Helium was used as the carrier gas, at a flow rate $1.0 \mathrm{ml} / \mathrm{min}$. The injector and detector temperatures were 220 and $250^{\circ} \mathrm{C}$, respectively (Abbas et al., 2016).

\section{Gas Chromatographic-Mass Spectrometric (GC- MS) analysis}

Isolation, identification, and quantification of the volatile compounds were performed using a gas chromatograph (Hewllet-Packard (5890)/mass spectrometry Hewlett- Packard-MS (5970) and operated with the MS Workstation software. The GC-MS system was equipped with DB-5 column (Varian, Inc. Walnut

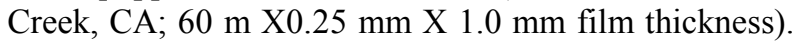
Column temperature began at $50^{\circ} \mathrm{C}$ and held for $10 \mathrm{~min}$, increased $3^{\circ} \mathrm{C}$ per minute to $180^{\circ} \mathrm{C}$, and finally increased $10^{\circ} \mathrm{C}$ per minute to $230^{\circ} \mathrm{C}$ and kept at this temperature for $10 \mathrm{~min}$. The constant column flow was $1 \mathrm{ml} / \mathrm{min}$, using helium as carrier gas. The linear retention index (Kovatsindex, KI) values for unknowns were 
determined based on retention time data obtained by analyzing a series of normal alkanes (C8-C22). Volatile components were positively identified by matching their KIs values and mass spectra with those of standards, also run under identical chromatographic conditions in the laboratory (Adams, 2007).

\section{Determination of phenolic compounds}

HPLC technique was used for the separation and quantification of phenolic compounds in pomegranate juices according to the method outlined by Mattila et al. (2000). The instrument (Agilent 1200 series, USA) was equipped with Zorbax column (4.6 x $250 \mathrm{~mm}) \mathrm{kept}$ in column compartment at $35^{\circ} \mathrm{C}$. Gradient elution was employed with a mobile phase consisting of $5 \mathrm{mM}$ $\mathrm{H}_{3} \mathrm{PO}_{4}, \mathrm{pH} 2.5$ and acetonitrile at a flow rate of 1 $\mathrm{ml} / \mathrm{min}$. A Multi-wavelength detector set at $280 \mathrm{~nm}$ was used. All phenolic compounds were quantified using external standard method.

\section{RESULTS AND DISCUSSION}

\section{Physicochemical properties}

The main physicochemical properties of the studied pomegranate juices are presented in Table (1). Fresh pomegranate juice contained $0.92 \mathrm{~g} / 100 \mathrm{ml}$ titratable acidity, $11.30 \mathrm{~g} / 100 \mathrm{ml}$ total sugars, 1.36 $\mathrm{mg} / 100 \mathrm{ml}$ ascorbic acid and $\mathrm{pH}$ value of 3.66. The CIE color coordinates of fresh juice were $\mathrm{L}^{*}$ (12.59), a* (1.40) and $b^{*}(-0.20)$. These values are consistent with those observed by Valero et al. (2014). Pasteurization and concentration did not show pronounced effects on titratable acidity, total sugars and $\mathrm{pH}$ value. Pasteurization had a marked effect on the degradation of ascorbic acid. Lower ascorbic acid content was observed in pasteurized juice (F1) and reconstitutedpasteurized juice (R1) than fresh juice and juice from cut back process (C). A noticeable effect of pasteurization on color parameters of pomegranate juices was also exhibited. The pasteurized juices (F1 and R1) had the lowest $L^{*}, a^{*}$ and $b^{*}$ values, indicating that thermal treatment during pasteurization had negative effect on color of pomegranate juice. Alper et al. (2005) stated that heat treatment significantly affected the color values of pomegranate juices. Vegara et al. (2013) found that pomegranate juice pasteurized at $90^{\circ} \mathrm{C}$ for 5 seconds lost $22 \%$ of the red color (measured as absorbance at $\mathrm{A}_{520}$ ). The primary color degradation in fruit juices containing anthocyanin (such as pomegranate juices) has been attributed to the degradation of monomers anthoyanins, polymerization and subsequent formation of brown pigments (Alighourchi and Barzegar, 2009). The improvement in color parameters and ascorbic acid retention of juice prepared by cut-back process compared to pasteurized juices is probably due to the inclusion of fresh pomegranate juice in the concentrate and to the fact that no further heat treatment was applied.

Table (1): Some physicochemical Properties of pomegranate juices

\begin{tabular}{|c|c|c|c|c|c|}
\hline Parameter & $\mathbf{F}$ & F1 & $\mathbf{R}$ & $\mathbf{R} 1$ & $\mathbf{C}$ \\
\hline Total Soluble Solids ( ${ }^{\circ}$ Brix) & 16.10 & 16.10 & 16.10 & 16.10 & 16.10 \\
\hline $\begin{array}{l}\text { Titratable Acidity (g/100 ml Anhydrous citric } \\
\text { acid) }\end{array}$ & 0.92 & 0.89 & 0.94 & 0.90 & 0.95 \\
\hline Total sugars $(\mathrm{g} / 100 \mathrm{ml})$ & 11.30 & 11.43 & 11.39 & 11.46 & 11.38 \\
\hline pH value & 3.66 & 3.61 & 3.63 & 3.64 & 3.64 \\
\hline Ascorbic acid (mg/100 ml) & 1.36 & 0.91 & 1.22 & 0.98 & 1.27 \\
\hline \multicolumn{6}{|l|}{ Color coordinates } \\
\hline $\mathbf{L}^{*}$ & 12.59 & 10.85 & 12.45 & 10.92 & 12.43 \\
\hline$a^{*}$ & 1.40 & 1.21 & 1.38 & 1.28 & 1.41 \\
\hline $\mathbf{b}^{*}$ & -0.20 & -0.16 & -0.21 & -0.14 & -0.21 \\
\hline
\end{tabular}

F: Fresh Juice, F1: Pasteurized Juice, R: reconstituted Juice, R1: Pasteurized-reconstituted Juice, C: Juice from Cut Back Process

\section{Flavor Volatiles}

Results presented in Table (2) show that in fresh pomegranate juice (F) a total of 27 compounds were identified: 7 monoterpenes, 6 esters, 5 aldehydes, 3 alcohols, 4 ketone, 1 ether and 1 alkane hydrocarbon. Calín-Sánchez et al. (2011) and Melgarejo et al. (2011) reported respectively 18 and 21 different aromatic compounds in Spanish pomegranates. Twenty three volatile compounds were found in the juices extracted from Wonderful cultivar (Vázquez-Araújo et al., 2011). On the other hand, Zhiying et al. (2016) identified a total of 36 volatile compounds in pomegranate juice using 3 different techniques for the extraction of the aromatic compounds.

Six esters (ethyl acetate, ethyl propanoate, isobutyl acetate, ethyl-2-methylbutyrate, ethyl-3methylbutyrate and ethyl hexanoate) were identified in fresh pomegranate juice (Table 2). They constituted $31.45 \%$ of the total peaks area. Pasteurization of pomegranate juice did not markedly change the level of esters $(32.6 \%$ of the total peaks area). Ethyl acetate and ethyl propanoate were the predominating esters. They 
contribute to floral and fruity smell. Reconstituted pomegranate juice showed lower level of esters $(9.82 \%)$ which was reduced to a value as low as $4.05 \%$ after pasteurization. This is mainly due to the loss of ethyl acetate and ethyl propanoate (Table 2). These results indicated that concentration is responsible for the low levels of esters identified in the juice. This effect is augmented when concentration is combined with pasteurization. On the other hand, pomegranate juice prepared by cut-back process retained high level of esters $(23.71 \%)$ due to the addition of fresh juice to pomegranate concentrate.

Table (2): Flavor volatiles composition of pomegranate juices

\begin{tabular}{|c|c|c|c|c|c|c|}
\hline Volatile compounds & $\mathbf{K I}^{\mathbf{a}}$ & $\mathbf{F}$ & F1 & $\mathbf{R}$ & $\mathbf{R 1}$ & $\mathbf{C}$ \\
\hline Ethyl acetate & 615 & 9.18 & 9.38 & 3.78 & n.d & 6.89 \\
\hline Ethyl propanoate & 687 & 6.95 & 7.18 & 2.19 & n.d & 4.76 \\
\hline Isobutyl acetate & 759 & 5.37 & 5.82 & 1.13 & 0.78 & 5.07 \\
\hline Hexanal & 803 & 3.51 & 3.43 & n.d & 9.51 & 0.93 \\
\hline trans-2-Hexenal & 841 & 2.78 & 2.65 & 0.96 & 2.92 & 1.13 \\
\hline Ethyl-2-methylbutyrate & 847 & 4.61 & 4.71 & 1.19 & 1.17 & 2.95 \\
\hline Ethyl-3-methylbutyrate & 853 & 2.59 & 2.65 & 0.84 & 0.95 & 3.16 \\
\hline cis-3-Hexenol & 857 & 15.08 & 14.29 & 5.45 & 10.37 & 13.76 \\
\hline$\alpha$-Pinene & 932 & 3.75 & 3.59 & 2.47 & 5.51 & 4.29 \\
\hline$\beta$-Pinene & 965 & 5.82 & 4.52 & 3.18 & 9.14 & 5.18 \\
\hline 1-Octen -3-one & 976 & 1.95 & 1.90 & 0.06 & 0.08 & 3.19 \\
\hline$\beta$-Myrcene & 988 & 3.64 & 3.62 & 1.24 & 1.29 & 1.38 \\
\hline Octanal & 1001 & 0.81 & 0.79 & 1.13 & 6.71 & 2.65 \\
\hline 3-Carene & 1003 & 0.16 & n.d & 1.15 & 0.83 & 0.06 \\
\hline Ethyl hexanoate & 1005 & 2.75 & 2.86 & 0.69 & 1.15 & 0.88 \\
\hline$\alpha$-Terpinene & 1012 & 1.84 & 1.16 & 0.73 & 0.79 & 5.02 \\
\hline 1,8-Cineole & 1027 & 0.67 & 0.59 & 1.25 & 0.04 & 7.35 \\
\hline Limonene & 1029 & 2.45 & 2.37 & 3.89 & 11.37 & 3.28 \\
\hline Phenylacetaldehyde & 1047 & 0.17 & 0.19 & 1.18 & 1.12 & 0.22 \\
\hline$\gamma$-Terpinene & 1058 & 1.69 & 1.64 & 0.05 & 2.63 & 1.53 \\
\hline Fenchone & 1084 & 2.44 & 2.51 & 1.26 & 0.38 & 6.13 \\
\hline Nonanal & 1102 & 6.82 & 7.93 & 0.79 & 9.10 & 0.95 \\
\hline Camphor & 1146 & 1.73 & 1.82 & 0.04 & 0.58 & 1.19 \\
\hline Terpinen-4-ol & 1173 & 3.82 & 3.77 & 1.19 & 0.32 & 0.06 \\
\hline$\alpha$-Terpineol & 1189 & 1.45 & 1.42 & 3.71 & 0.82 & 2.64 \\
\hline Dodecane & 1199 & 1.18 & 0.93 & 0.03 & 0.03 & 1.12 \\
\hline$\beta$-Damascenone & 1396 & 0.16 & 0.08 & 0.85 & 0.06 & 0.79 \\
\hline
\end{tabular}

F: Fresh juice, F1: Pasteurized juice, R: reconstituted juice, R1: Pasteurized-reconstituted juice, C: Juice from Cut Back process,

${ }^{\mathrm{a}}$ : Kovats Index

The obtained results are in agreement with Belitz et al. (2009) who reported that esters are significant aroma constituents of many fruits and plants and are synthesized only by intact cells, but during the processing of the plant material, esters are rapidly hydrolyzed and the fruity aroma flattens. Table (2) shows also that 3-carene was not detected in pasteurized juice. Among the identified alcohols cis-3-Hexenol was found in highest concentration, representing $15.08 \%$ of the total peaks area. It is characterized by an intense grassy-green odor of freshly cut green grass and leaves. Pasteurization did not affect the level of cis-3-hexenol, but concentration step had greater impact. Reconstituted juice contained the lowest level of this alcohol (5.45\%), whereas juice from cut-back process retained high level $(13.76 \%)$. Terpenes ( $\alpha$-pinene, $\beta$-pinene, $\beta$-myrcene, 
limonene and $\gamma$-Terpinene, $\alpha$-terpinene) are present in moderate concentration. They contribute to fresh flavor. Although reconstituted pasteurized juice (R1) showed the highest level of terpenes $(31.50 \%$ of the total peaks area) but this is mainly due to the fact that the loss of the 2 esters was reflected proportionally on the other volatile compounds (such as $\alpha$-pinene, limonine and nonanal). These results are in accordance with those reported by Nisperos-Carriedo and Shaw (1990). They found that unpasteurized and pasteurized single-strength juices not made from concentrate did not show marked changes in the profile of flavor component when compared to fresh juice. In contrast, pasteurized reconstituted juices from concentrate showed decreased acetaldehyde, methyl acetate, methyl butyrate and ethyl butyrate. Koppel et al. (2015) stated that the most differentiated juice was the reconstituted sample with fermented and brown flavors, while fresh, fresh frozen and pasteurized samples did not vary as much.

\section{Phenolic compounds}

A total of 23 phenolic compounds were identified in pomegranate juices, except pasteurized juice which contained 22 compounds (Table 3). Phenolic compounds of clear pomegranate juice consisted of 15 phenolic acids, pyrogallol, catechin, chatechol, epicatechin, caffeine, resveratrol, oleuropein and coumarin. The major phenolic compounds identified and quantified in fresh pomegranate juice in deceasing order (as $\mathrm{mg} / 100 \mathrm{ml}$ juice) were pyrogallol (36.39), catechin (9.12), chatechol (5.76) and protocatchuic acid (5.74). Mena et al. (2012) detected 21 phenolic compounds in pomegranate juice. The phenolic acids present in pomegranate juice were found to be divided into 2 groups: hydroxybenzoic acids, mainly gallic acid and ellagic acid and hydroxycinnamic acids, principally caffeic acid, chlorogenic acid, and p-coumaric acid (Poyrazoglu et al., 2002).

Table (3): Phenolic compound contents of pomegranate juices

\begin{tabular}{|c|c|c|c|c|c|}
\hline \multirow{2}{*}{ Phenolic compound } & \multicolumn{5}{|c|}{ Concentration $(\mathrm{mg} / 100 \mathrm{ml})$} \\
\hline & $\mathbf{F}$ & F1 & $\mathbf{R}$ & R1 & $\mathbf{C}$ \\
\hline Gallic acid & 1.22 & 1.44 & 1.37 & 1.40 & 2.00 \\
\hline Pyrogallol & 36.39 & 15.98 & 52.58 & 40.81 & 58.70 \\
\hline 4-Amino benzoic acid & 0.57 & 1.20 & 0.45 & 1.01 & 1.10 \\
\hline Protocatchuic acid & 5.74 & 7.00 & 5.26 & 4.76 & 8.52 \\
\hline Catechin & 9.12 & 10.68 & 10.11 & 5.85 & 13.45 \\
\hline Chlorogenic acid & 1.00 & 1.10 & 1.06 & 1.07 & 1.48 \\
\hline Chatechol & 5.76 & 6.43 & 5.33 & 5.24 & 8.85 \\
\hline Epi-catechin & 0.52 & 0.79 & 1.32 & 0.81 & 0.72 \\
\hline Caffeine & 0.28 & 0.43 & 0.24 & 1.14 & 1.13 \\
\hline P-OH-benzoic acid & 2.22 & 2.63 & 2.52 & 3.43 & 5.82 \\
\hline Caffeic acid & 0.11 & 0.053 & 0.12 & 0.15 & 0.16 \\
\hline Vanillic acid & 0.3 & 0.00 & 0.24 & 0.37 & 0.31 \\
\hline P-Coumaric acid & 0.18 & 0.48 & 0.21 & 0.27 & 0.25 \\
\hline Ferulic acid & 0.16 & 0.5 & 0.16 & 0.19 & 0.17 \\
\hline Iso-Ferulic acid & 0.06 & 0.2 & 0.08 & 0.07 & 0.09 \\
\hline Resveratrol & 0.02 & 0.06 & 0.01 & 0.02 & 0.03 \\
\hline Oleuropein & 3.22 & 6.24 & 3.21 & 2.79 & 4.11 \\
\hline Ellagic acid & 0.37 & 1.94 & 0.69 & 0.48 & 0.38 \\
\hline$\rho$-Coumaric acid & 0.06 & 0.15 & 0.05 & 0.06 & 0.07 \\
\hline Benzoic acid & 0.69 & 0.91 & 0.75 & 0.75 & 0.04 \\
\hline $3,4,5$-Triethoxy cinnamic acid & 0.04 & 0.14 & 0.018 & 0.03 & 0.04 \\
\hline Coumarin & 0.03 & 0.09 & 0.01 & 0.03 & 0.03 \\
\hline Salicylic acid & 0.08 & 0.34 & 0.05 & 0.05 & 0.07 \\
\hline Total & 68.09 & 58.58 & 85.83 & 67.65 & 102.24 \\
\hline
\end{tabular}


Pasteurization caused pronounced decrease in phenolic compounds content. Phenolic compounds content in fresh pomegranate juice accounted for 68.09 $\mathrm{mg} / 100 \mathrm{ml}$ which was decreased to $58.58 \mathrm{mg} / 100 \mathrm{ml}$ in pasteurized juice (Table 3 ). This is mainly due to reduction in pyrogallol concentration by $56.09 \%$. According to Alper et al. (2005) the thermal treatment applied to pomegranate juice affected their total phenol amount. The effect of pasteurization on total phenol reduction was $7.1 \%$. Mena et al. (2013) stated that pasteurization resulted in significant reduction $(60 \%)$ of ellagic acid. On the other hand, concentration process resulted in higher content of total phenolic compounds in reconstituted juice $(85.83 \mathrm{mg} / 100 \mathrm{ml})$ which upon pasteurization was reduced to $67.65 \mathrm{mg} / 100 \mathrm{ml}$. Pomegranate juice prepared from cut back process was characterized by the highest phenolic contents $(102.24$ $\mathrm{mg} / 100 \mathrm{ml}$ ). Total phenolic content ranged from 58.8 to $255.1 \mathrm{mg} / 100 \mathrm{ml}$ of pomegranate juice (GomezCaravaca et al., 2013).

\section{CONCLUSION}

In conclusion processing had an effect on pomegranate juice properties and the effect is different depending on the processing method. Pasteurization and concentration of pomegranate have an impact on ascorbic acid content, color parameters, Flavor profiles, as well as phenolic compounds. Cut-back process could be a promising technique in producing better quality juice.

\section{REFERENCES}

Abbas, H. M., A. Hussien and G. E. Ibrahim (2016). Changes in antioxidant activity and volatile compounds of functional yoghurt fortified with rice bran during storage. J. Chem. Pharm. Res., 8(7): 761-766.

Adams R. (2007). Identification of essential oil components by gas chromatography/mas spectrometry, Allured Publishing Carol Steam Ilionois, USA.

AIJN (2008). Association of the Industry of Juices and Nectars from Fruits and vegetables of the European Union. Reference Guideline for Pomegranate Juice. Code of Practice for Evaluation of fruit and Vegetable Juices, 6: 21.

Alighourchi, H. and M. Barzegar (2009). Some physicochemical characteristics and degradation kinetic of anthocyanin of reconstituted pomegranate juice during storage. Journal of Food Engineering, 90: 179-185.

Alper, N., K. S. Bahceci and J. Acar (2005). Influence of processing and pasteurization on color values and total phenolic compounds of pomegranate juice. Journal of Food Processing and Preservation, 29(5-6): 357-368.

AOAC (2005). Official Methods of Analysis. $18^{\text {th }}$ ed. Association of Official Analytical Chemists; Arlington, VA, USA.

Ashoush, S. and M. G. E. Gadallah (2012). Effects of different heating methods on the quality characteristics of pomegranate juice concentrates. Egypt. J. Food Sci., 40: 1-14.
Ashurst, P. (2013). Production and packaging of noncarbonated fruit juices and fruit beverages. Springer Science \& Business Media, pp. 76.

Belitz, H. D., W. Grosch and P. Schieberle (2009). Food Chemistry. $4^{\text {th }}$ ed. Springer, Berlin (Germany), pp. 93-157.

Caleb, O. J., O. A. Fawole, R. R. Mphahlele and U. L. Opara (2015). Impact of preharvest and postharvest factors on changes in volatile compounds of pomegranate fruits and minimally processed arils. Scientia Horticulturae, 188: 106-114.

Calín-Sánchez. A., J. J. Martínez Nicolás, L. VázquezAraújo and A. Carbonell-Barrachina (2011). Volatile composition and sensory quality of Spanish pomegranates (Punica granatum L.). Journal of the Science of Food and Agriculture, 91(3): 586-92.

Carbonell-Barrachina A. A., A. Calín-Sánchez, B. Bagatar, F. Hernández, P. Legua, R. MartínezFont and P. Melgarejo (2012). Potential of Spanish sour-sweet pomegranates (cultivar C25) for the juice industry. Food Sci Technol Int., 18(2): 129-38.

Cassano, F.; C. Conidi and E. Drioli (2011). Clarification and concentration of pomegranate juice (Punica granatum L.) using membrane processes. Journal of Food Engineering, 107(3-4):366-373.

Fellers, P. J. (2006). Shelf life and quality of freshly squeezed, unpasteurized, polyethylene-bottled citrus juice. Journal of Food Science, 53(6): $1699-1702$.

Fischer, U. A., R. Carle and D. R. Kammerer (2011). Identification and quantification of phenolic compounds from pomegranate (Punica granatum L.) peel, mesocarp, aril and differently produced juices by HPLC-DADESI/MSn. Food Chemistry, 127(2): 807-821.

FSSAI (2012). Fruit and vegetable products. In: manual methods of analysis of foods. Food Safety and Standards Authority of India, Manual lab 5, Ministry of Health and Family Welfare Government of India, New Delhi, pp. 12-14.

Gomez-Caravaca, A. M., V. Verardo, M. Toselli, A. Segura-Carretero, A. Fernandez-Gutierrez and M. F. Caboni (2013). Determination of the major phenolic compounds in pomegranate juices by HPLC-DAD-ESI-MS. Journal of Agricultural and Food Chemistry, 61(22): 5328-5337.

Güler, Z. (2007). Changes in salted yoghurt during storage. Int. J. Food Sci. and Techn, 42: 235237.

Halliwel, B. (2002). Food-derived antioxidants: how to evaluate their importance. In: Food and in Vivo in Handbook of Antioxidants, Cadenas, E. Packer, L.(Eds.), $2^{\text {nd }}$ ed. Mercel Dekkar, New York (USA), pp. 18-63.

Heber, D. (2011). Pomegranate Ellagitannins. In: Herbal Medicine Benzie IFF, Wachtel-Galor S. (eds): Biomolecular and Clinical Aspects. $2^{\text {nd }}$ edition. 
CRC Press/Taylor \& Francis, Chapter 10, pp. 101-191.

Jiao, B., A. Cassano and E. Drioli (2004). Recent advances on membrane processes for the concentration of fruit juices: a review. Journal of Food Engineering, 63(3): 303-324.

Johanningsmeier, S. D. and G. K. Harris (2011). Pomegranate as a functional food and nutraceutical source. Annual Reviews in Food Science and Technology, 2: 181-201.

Kahramanoglu, I. and S. Usanmaz (2016). Pomegranate Production and Marketing, CRC Press, Taylor \& Francis, pp. 14-19.

Koppel, K., L. E. Anderson and E. Chambers (2015). Influence of processing on pomegranate (Punica granatum L.) juice flavor and aroma. Journal of the Science of Food and Agriculture, 95(5): 1066-1071.

Kumar, S. S., M. Ashish and J. Jyoti (2013). Concentration of fruit juices by vacuum membrane distillation: A review. International Journal of Chemistry and Chemical Engineering, 3(2): 49-54.

Mattila, P., J. Astola and J. Kumpulainen (2000). Determination of flavonoids in plant material by HPLC with diode-array and electro-array detection. J. Agric. Food Chem., 48: 58345841.

Mayuoni-Kirshinbaum, L. and R. Porat (2014). The flavor of pomegranate fruit: a Review. Journal of the Science of Food and Agriculture, 94(1): 21-27, 2014.

McLaren, K. (1980). Food colorimetry. In: Developments in food colors-I, J. Walford (Ed.), Applied Science Publishers Ltd, London, UK, pp 27-45.

Melgarejo, P., Á. Calín-Sánchez, L. VázquezAraújo and A. A. Carbonell-Barrachina (2011). Volatile composition of pomegranates from 9 Spanish cultivars using headspace solid phase microextraction. Journal of Food Science, 76(1): 14-20.

Mena, P., L. Calani, C. Dall'Asta, G. Galaverna, C. Garcia-Viguera, R. Bruni, A. Crozier and D. del Rio (2012). Rapid and comprehensive evaluation of (ploy) phenolic compounds in pomegranate (Punica granatum L.) Juice by UPLC-MS. Molecules, 17(12): 14821-14840.

Mena, P., N. Marti, D. Saura, M. Valero and C. GarciaViguera (2013). Combinatory effect of thermal and blending on the quality of pomegranate juices. Food Bioproc. Tech., 6 (11): 31863199.

Mphahlele, R. R., O. J. Caleb, O. A. Fawole and U. L. Opara (2016). Effect of different maturity stages and growing locations on changes of chemical, biochemical and aroma volatile composition of Wonderful pomegranate juice. Journal of the Science of Food and Agriculture, 96(3): 1002-1009.

Nisperos-Carriedo, M. O and P. E. Shaw (1990). Comparison of volatile flavor components in fresh and processed orange juices. J. Agric. Food Chemistry, 38: 1048-1052.

Nuncio-Jauregui, N., A. Calín-Sánchez, L. VázquezAraújo, A. Pérez-López, M. Frutos-Fernández and A. Carbonell-Barrachina (2014). Processing of pomegranate juice and impact on bioactive components. In: Beverages. V. Preedy (ed.), Elsevier Publisher, Chapter 76, pp. 629-636.

Poyrazoglu, E., V. Gökmen and N. Artı (2002). Organic acids and phenolic compounds in pomegranates (Punica granatum L.) grown in Turkey. J Food Comp Anal, 15: 567-75.

Sanchez, J., Y. Ruiz, J. M. Auleda, E. Hernandez and M. Ravento's (2009). Review. Freeze concentration in the fruit juices industry. Food Science and Technology International, 15(4): 303-315.

Shatta, A. (2006). Effect of frozen storage and concentration methods on some quality parameters of lime juice and concentrates $\mathrm{J}$. Agric. Sci. Mansoura Univ., 31(9): 6111-6123.

Valero, M., S. Vegara, N. Martí and D. Saura (2014). Clarification of pomegranate juice at industrial scale. J Food Process Technol., 5(5): 324-330.

Vázquez-Araújo, L., E. Chambers, K. Adhikari and A. A. Carbonell-Barrachina (2011). Physicochemical and sensory properties of pomegranate juices with pomegranate albedo and carpellar membranes homogenate. LWT Food Science and Technology, 44: 2119-2125.

Vegara, S., N. Marti, P. Mena, D. Saura and M. Valero (2013). Effect of pasteurization process and storage on color and shelf-life of pomegranate juices. LWT-Food Science and Technology, 54(2): 592-596.

Yousefi S., Emam-Djomeh, Z. Mousavi, S. M. A. and G. R. Askari (2012). Comparing the effects of microwave and conventional heating methods on the evaporation rate and quality attributes of pomegranate (Punica granatum L.) juice concentrate. Food Bioprocess Technology, 5(4):1328-1339.

Zhiying Yi, T. Feng, H. Zhuang, R. Ye, M. Li and T. Liu (2016). Comparison of different extraction methodsin the analysis of volatile compounds in pomegranate juice. Food Anal. Methods (2016) 9: 2364-2373. 


\section{تأثير التصنيع على مركبات النكهة الطيارة والخواص الفيزيوكيمائية لعصير الرمان}

هيام توفيق علام

معهد بحوث تكنولوجيا الأغذية - مركز البحوث الزر اعبة جيزة - جمهورية مصر العربية

تهدف الدراسة إلى البحث في تأثير عمليتي البسترة وتقنية التركيز على بعض الخواص الفيزيوكيمائية، مركبات النكهة الطيارة

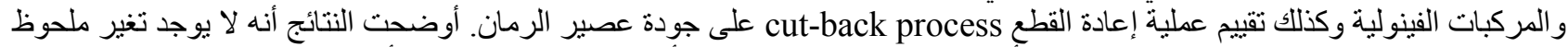

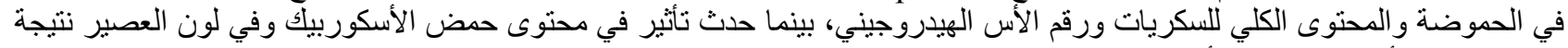

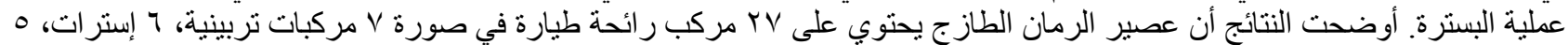

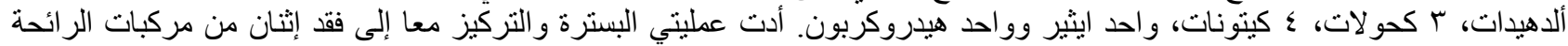

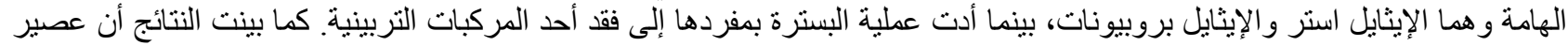

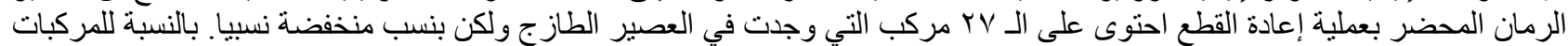

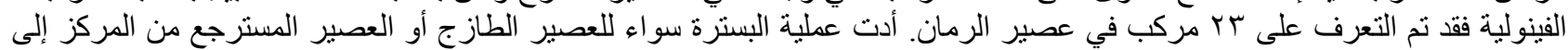

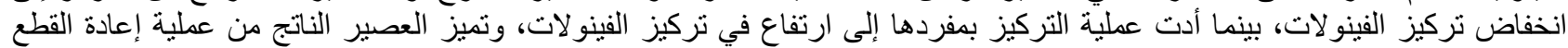

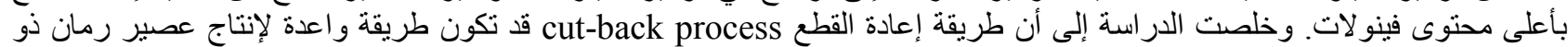


رقم الإيداع بدار الكتب

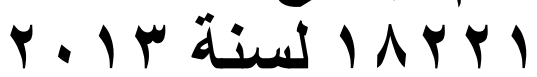



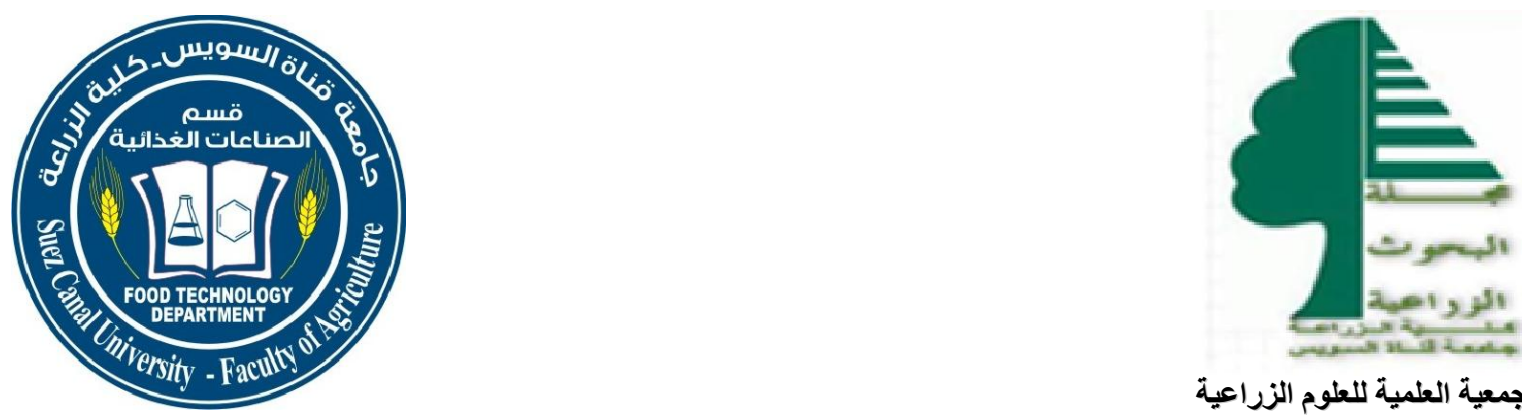

الجمعية العلمية للعلوم الزراعية

ISSN: 2314-7970

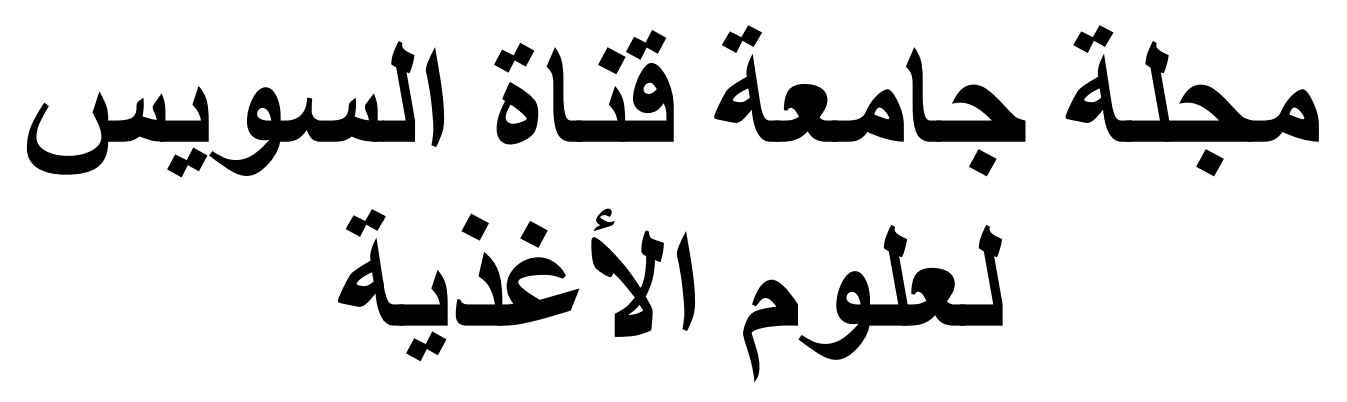

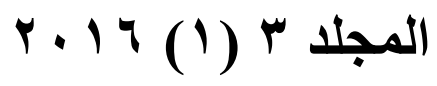

تصدر ها:

الجمعية العلمية للعلوم الزر اعية - جامعة قناة السويس - الإسماعيلية - جمهورية مصر العربية. 